\title{
I have it!
}

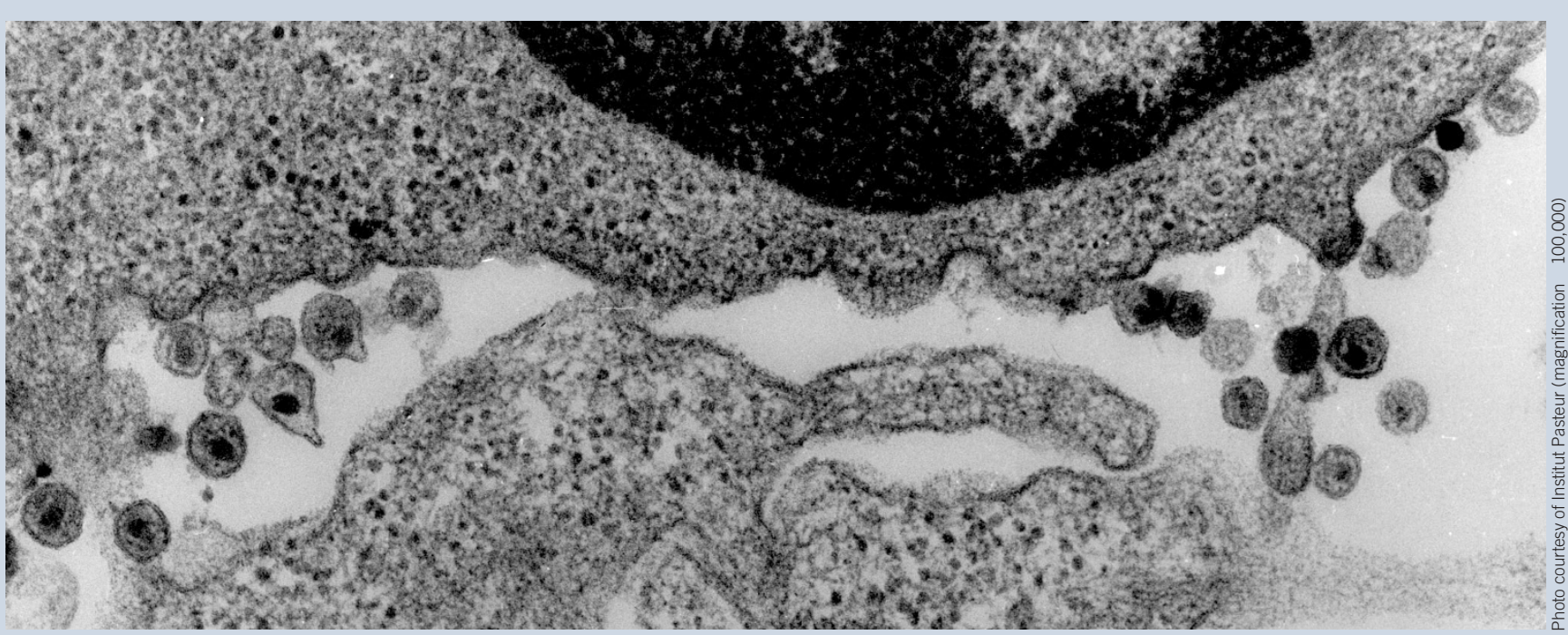

It happened on Friday, 4 February 1983, at 5:45 p.m. A week before, Monsieur Montagnier had come to see me in my laboratory one evening to ask me whether l'd agree to work on an infectious human sample. I agreed straight away. He recommended that I take all possible precautions; at that time we only had a simple laminar flow hood.

Before turning off the electron microscope, I had to let it cool down. That late Friday afternoon, just as I was about to turn off the cooling water, I saw a virus under the screen. I ran out of the lab, screaming, "I have it, I have it!" Someone walking in the corridor at that moment might have doubted my mental capacities. I immediately took several photos. Time flew by. Later that evening, I arrived at the railway station to take the train to Trouville, where I was planning to spend the weekend, only to see the red taillights of the departing train.

I didn't get to the Normandy coast, but that weekend was probably the most intense experience in my 39 years doing electron microscopy at the Pasteur Institute.

After that, I hardly left the electron microscope. It was often tiring, particularly on the eyes-tiring but productive. Examining viral cultures, I saw the virus stick to the cell surface, sometimes disappearing inside, which was a sign of infection. The budding process, a sign of productive infection, was readily visible. And of course, I also saw cells with altered morphology and others killed by the virus.

I was surprised by the appearance of the virus. Viruses with a similar morphology had been described in goats and horses, but nothing like this had ever been described for a human virus. Because I was looking at cells of human origin, I was convinced that we had the first human virus of that family. I remember saying to myself that it would be possible to make a vaccine. I was a bit naive, or at least optimistic, at that moment.

Charlie Dauguet, as told to Hugues Fleury and Simon Wain-Hobson

questions, Dauguet detected retroviral-like particles within a few days. His images showed characteristic immature particles budding at the plasma membrane. We began to accumulate data indicating that we were dealing with a retrovirus, such as the association of reverse transcriptase and RNA in particles at a density of 1.16 in a sucrose gradient, a characteristic of most retroviruses. By immunofluorescence analysis, we identified antibodies against the virus in the serum of both the first patient and a second patient. The virus was not recognized by type-specific antisera to HTLV-1 (provided by R. Gallo), indicating that we were dealing with an unknown virus.
It was a very exciting period for our group, and we completely forgot how many hours we were spending in the laboratory each day. All of our data were corresponding precisely with what we expected. Although we began to realize the importance of our discovery, our aim was to continue working and to generate data that would convince the scientific community.

In May 1983, our early data led to the publication in Science of the initial description of the AIDS-causing virus, named lymphadenopathy-associated virus, which was later designated human immunodeficiency virus-1 (HIV-1)2. From 1983 to 1985 , a vast amount of data was accumulated through further collaborations between scientists and clinicians and contributions from Robert Gallo's laboratory, which strongly reinforced our initial findings. The detection of antibodies against the virus in individuals at risk for AIDS and in those with AIDS or AIDS-related conditions, but not in individuals suffering from other diseases, confirmed that HIV was responsible for the disease ${ }^{3}$. The virusselective tropism for $\mathrm{CD} 4^{+} \mathrm{T}$ cells ${ }^{4}$, leading to $\mathrm{T}$ cell death, was demonstrated early in 1983 in collaboration with Klatzmann and Gluckman. The viral reverse transcriptase was characterized, providing further evidence that we were dealing with a retrovirus $^{5}$. The cloning of the virus in 1984 (ref. 6) and the sequencing of its genome ${ }^{7}$ 